\title{
Influence of e-beam irradiation on the chemical and crystal structure of poly(aliphatic/aromatic-ester) multiblock thermoplastic elastomers
}

\author{
Miroslawa El Fray ${ }^{* 1}$, Marta Piątek-Hnat ${ }^{1}$, Judit E. Puskas ${ }^{2}$, Elizabeth Foreman-Orlowski ${ }^{2}$ \\ ${ }^{1}$ West Pomeranian University of Technology, Szczecin, Biomaterials and Microbiological Technologies, ul. Pulaskiego 10, \\ 70-322 Szczecin, Poland \\ ${ }^{2}$ Department of Polymer Science, The University of Akron, Akron, OH 44325, USA \\ * Corresponding author: e-mail: mirfray@zut.edu.pl
}

\begin{abstract}
Poly(aliphatic/aromatic-ester) (PED) multiblock copolymers belong to the class of thermoplastic elastomers (TPEs), characterized by a physical network of semi-crystalline hard segments. The PEDs were modified with e-beam to create an additional network structure. Polymers were evaluated using SEC, WAXS, DSC and quasi-static tensile tests. E-beam irradiation induced a significant increase of molecular weight and tensile strength of the PEDs. This effect, together with the diminished degree of crystallinity can be explained by the formation of chemical crosslinks, which are located in the hard phase segments.
\end{abstract}

Keywords: biopolymers, thermoplastic elastomers, e-beam irradiation, multiblock polyesters, DSC.

\section{INTRODUCTION}

Thermoplastic elastomers (TPEs) are polymeric materials, which combine the mechanical properties of vulcanized rubbers with the processability and recyclability of thermoplastics. Multiblock-type thermoplastic elastomers (TPEs) such as poly(ether-ester)s or poly(ether-amides) contain at least two types of chemically attached incompatible polymeric blocks. While macroscopically homogeneous, these polymers phase separate on a microscopic (nanometer) scale. The discreet plastic phases embedded in the continuous elastomer phase provide "physical crosslinks" and self-assemble to form a stable but thermally reversible structure. They can be tailor-made by using simple step growth polymerization processes with precisely adjusted amount of constituting blocks (segments) on the feed. Their properties are changing with composition, starting from soft "rubber-like" materials to hard and stiff "thermoplastic-like" polymers. TPE can be easily modified by chemical and physical methods in order to change surface characteristics or mechanical performance. If good fatigue properties (low creep) are required, they can be modified with e-beam radiation ${ }^{1,2}$.

In our work we investigate multiblock poly(aliphatic/ aromatic-ester) copolymers (PED) recently developed for medical applications. These PEDs are transparent at $<50$ wt. $\%$ hard segment content and they resemble medical-grade silicone rubber. The PED copolymers contain hard domains of an aromatic ester, poly(butylene terephthalate) (PBT), and soft segments composed of hydrogenated and distilled dimerized fatty acid (vegetable derived liquid fatty acid, abbreviated here as (di) linoleic acid, DLA), creating aliphatic ester sequences upon reaction with glycol. Since these poly(aliphatic/ aromatic-ester)s show biocompatibility in vitro and in vivo ${ }^{3-6}$, their resistance to potential radiolysis when sterilized or e-beam modified is of great importance ${ }^{7}$. We already demonstrated that PED copolymers showed enhanced stability toward ionizing radiation without sign of stable free radicals formation ${ }^{7}$. In this paper, we focused on the chemical and crystal structure changes upon PED modification with various dosages of e-beam irradiation. The effect of observed changes on thermal and mechanical properties will be discussed.

\section{EXPERIMENTAL}

\section{Materials and synthesis}

The materials for this study are segmented polyesters containing poly(butylene terephthalate) (PBT) sequences (hard segments) extended with the butylene ester of dimerized fatty acid (DLA), abbreviated here as (di) linoleic acid (soft segments). The semi-crystalline PBT is the hard segment phase while DLA is an amorphous material, which imparts the elastomeric characteristic to the polymer and therefore represents the soft segments phase. The biocompatibility of PBT and DLA has been well established and both can be used as a biomaterial or as blend components. The chemical structure of the segmented PED copolymer is shown in Fig. 1.

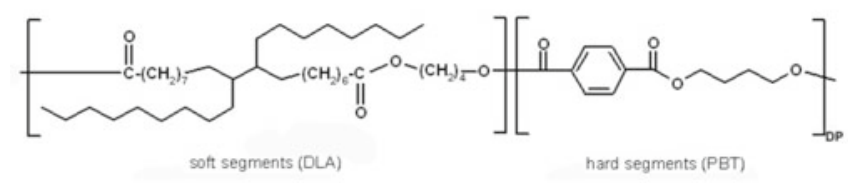

Figure 1. Chemical structure of poly(aliphatic/aromatic-ester) (PED) multiblock copolymers

In this study, two hard/soft segment ratios were investigated (PBT-26 and PBT-30) containing 26 wt.- $\%$ PBT and 74 wt.- $\%$ DLA, and 30 wt.- $\%$ PBT and 70 wt.- $\%$ DLA, respectively.

The segmented PED multiblock copolymers were obtained in a two-stage process of transesterification and polycondensation from the melt, which was described in previous publications $\mathbf{3}^{3,6}$.

\section{Irradiation}

After polymerization, the materials were first compression-moulded and then e-beam irradiated at the Institute of Nuclear Chemistry and Technology (Warsaw). A linear electron accelerator Elektronika $10 / 10$ was used to generate a $10 \mathrm{MeV}$ beam for different dosages, namely 50,75 and $100 \mathrm{kGy}$ at room temperature.

\section{Size exclusion chromatography (SEC)}

The molecular weight $\left(M_{n}, M_{w}\right)$ and molecular weight distribution $\left(\mathrm{M}_{\mathrm{w}} / \mathrm{M}_{\mathrm{n}}\right)$ of the block copolymers were 
determined by Size Exclusion Chromatography (SEC) using a Waters system equipped with six Styragel-HR column $(106,105,104,103,500$, and $100 \AA$ pore sizes), thermostated at $35^{\circ} \mathrm{C}$, a Waters 410 DRI detector thermostated at $40^{\circ} \mathrm{C}$, a Dawn DSP 18 angle laser light scattering detector (MALLS) (Wyatt Technology), and a Waters 996 UV detector. The mobile phase for the SEC was tetrahydrofuran (THF) at $1 \mathrm{ml} / \mathrm{min}$, continuously distilled off $\mathrm{CaH}_{2}$ and recirculated. The ASTRA ${ }^{\circledR}$ software (version 5.3.2.14) was used to obtain MW data calculate using $\mathrm{dn} / \mathrm{dc}=0.183$ given for polystyrene (polystyrene equivalent $\mathrm{M}_{\mathrm{W}}$ ) and also, assuming $100 \%$ mass recovery. This method gave good agreement with $\mathrm{M}_{\mathrm{W}}$ data obtained by assuming $100 \%$ mass recovery on the columns.

\section{Differential scanning calorimetry (DSC)}

Differential scanning calorimetry (DSC) scans were performed with a TA Instruments (DSC Q100) apparatus. The samples were dried in vacuum at $60^{\circ} \mathrm{C}$, and then kept in a desiccator. The process was carried out in a triple cycle: first heating, then cooling, and second heating in the temperature range from $-100 \mathrm{C}$ to $50^{\circ} \mathrm{C}$ higher than the melting point of the hard phases of each copolymer. The rate of heating and cooling was $10^{\circ} \mathrm{C}$ $\mathrm{min}^{-1}$. In addition, the melting enthalpy $\Delta \mathrm{H}_{\mathrm{m}}$ (second heating) of PBT and the mass content of PBT crystallites $\mathrm{w}_{\mathrm{c}}$ were calculated.

\section{Wide-angle X-ray scattering (WAXS)}

WAXS spectra were recorded at room temperature and $2 \theta$ values between $10^{\circ}$ and $38^{\circ}$ were obtained at a rate of $0.5^{\circ} / \mathrm{min}$ with 0.02 steps. The TUR M62 X-ray Diffractometer set in reflection mode was operated at $40 \mathrm{kV}$ and $30 \mathrm{~mA}$ with a $\mathrm{Cu}-\mathrm{K} \alpha$ radiation wavelength of $1.542 ~ \breve{A}$. To prepare for the experiment, thin film specimens of both the neat and after e-beam irradiation thermoplastic elastomers were prepared via compression molding.

\section{Tensile testing}

The quasi-static tensile data were collected at room temperature with an Instron TM-M tensile tester equipped with a $500 \mathrm{~N}$ load cell employing a crosshead speed of $100 \mathrm{~mm} / \mathrm{min}$ according PN-ISO 527-1:1998. The starting clamp distance was $25 \mathrm{~mm}$. The obtained results were averaged from 6 specimens with cross section of $0.5 \times 4 \mathrm{~mm}$.

\section{Gel fraction}

The gel fraction was measured by extraction. Small pieces of polymer films $(0.1-0.2 \mathrm{~g})$ were placed in Schott's crucibles (P2 type) and extracted with boiling THF $\left(100 \mathrm{~cm}^{3}\right)$ for $3 \mathrm{~h}$. The samples were then dried and weighed in order to calculate the gel fraction using equation (1):

$\mathrm{X}=\left(\mathrm{m}_{1} / \mathrm{m}_{0}\right) * 100 \%$

where: $m_{1}$ - mass of dried sample after extraction $\mathrm{m}_{0}-$ mass of sample before extraction

\section{RESULTS AND DISCUSSION}

\section{Size exclusion chromatography (SEC)}

Fig. 2 shows the high resolution SEC traces. In general, polymer of lower hard segments content, PED-26 (Fig 2a) showed a multimodal distribution (especially after radiation modification) with high $\mathrm{M}_{\mathrm{W}}$ shoulder in the MALLS curve while material containing higher content of hard segments, PED-30 (Fig 2b) showed multimodal distribution.
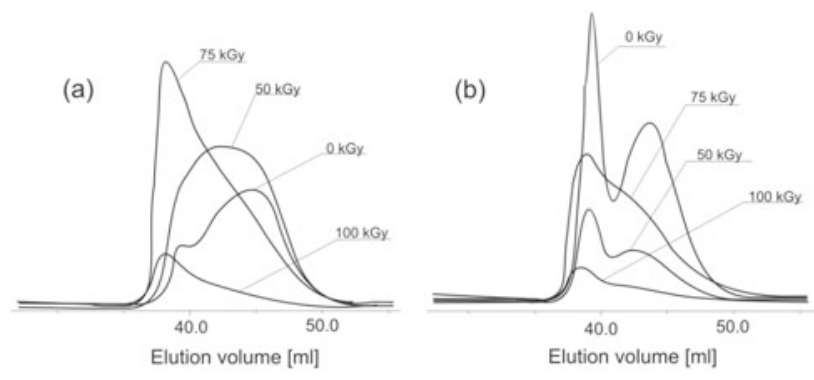

Figure 2. . SEC traces of PED-26 (a) and PED-30 (b) copolymers before and after e-beam irradiation

There is a high $\mathrm{M}_{\mathrm{W}}$ shoulder $(8800 \mathrm{~g} / \mathrm{mol})$ in the SEC trace of the neat PED-26 (0 kGy), with the main peak centering around $45 \mathrm{ml}$. The main peak shifted to higher molecular weights after irradiation. At $100 \mathrm{kGy}$ the material gelled (the gel fraction determined from Soxhlet extraction was $67 \%$ ), therefore the small amount of soluble fraction yielded a low intensity signal.

In the case of PED-30, the high $\mathrm{M}_{\mathrm{W}}$ peak is more prominent $(12600 \mathrm{~g} / \mathrm{mol})$. Similarly to the PED-26, the lower $M_{W}$ peak shifted towards higher $M_{W}$, reaching the peak $\mathrm{M}_{\mathrm{W}}$ of the high fraction. Again, at $100 \mathrm{kGy}$ the material gelled (the gel fraction determined from Soxhlet extraction was 75\%), and the small amount of soluble fraction yielded a low intensity signal. Comparison of retention volume changes of the lower $\mathrm{M}_{\mathrm{W}}$ maximum peak (a) and the higher $\mathrm{M}_{\mathrm{W}}$ maximum peak (b) for PED-30 with the increasing radiation dose are presented in Fig.3.

As the effect of e-beam irradiation of PED-26 and PED-30 differing in hard segments content, different character of $M_{n}$ changes with increasing radiation dose was observed (Fig. 4). PED-26 is a polymer where calculated degree of polycondensation (on the monomers feed) was $\approx 1$. It means that such material should be considered as a homogenous mixture of hard and soft segments rather than multiblock polymer with well defined hard and soft phases. Therefore, increasing radiation dose has no significant effect on $\mathrm{M}_{\mathrm{n}}$ changes for PED-26 (Fig. 4), while for PED-30 (degree of polycondensation $=1,3), M_{n}$ increases with increasing radiation dose, thus indicating that e-beam radiation is affecting mainly hard domains structure and introduces more cross-links into PED-30 copolymer.

The summary of GPC/SEC numbers for PED-26 and PED-30 is given in Table 1.

\section{Thermal properties}

Formation of a physical (native) and chemical (after modification) double network was also investigated by 
Table 1. GPC/SEC characteristics for PED-26 and PED-30 multiblock copolymers

\begin{tabular}{|c|c|c|c|c|c|c|c|c|c|c|c|c|}
\hline Sample & $\begin{array}{c}\text { Concen- } \\
\text { tration } \\
{[\mathrm{mg} / \mathrm{ml}]}\end{array}$ & $\begin{array}{l}\mathrm{dn} / \mathrm{dc} \\
{[\mathrm{mL} / \mathrm{g}]}\end{array}$ & $\mathrm{M}_{\mathrm{w}} / \mathrm{M}_{\mathrm{n}}$ & $\begin{array}{c}\mathrm{M}_{\mathrm{n}} \\
{[\mathrm{g} / \mathrm{mol}]}\end{array}$ & $\begin{array}{c}\mathrm{M}_{\mathrm{w}} \\
{[\mathrm{g} / \mathrm{mol}]}\end{array}$ & $\begin{array}{c}\mathrm{M}_{\mathrm{z}} \\
{[\mathrm{g} / \mathrm{mol}]}\end{array}$ & $\begin{array}{c}R_{n} \\
{[\mathrm{~nm}]}\end{array}$ & $\begin{array}{c}\mathrm{R}_{\mathrm{w}} \\
{[\mathrm{nm}]}\end{array}$ & $\begin{array}{c}R_{z} \\
{[\mathrm{~nm}]}\end{array}$ & $\begin{array}{c}\eta_{\mathrm{n}} \\
{[\mathrm{mL} / \mathrm{g}]}\end{array}$ & $\begin{array}{c}\eta_{w} \\
{[\mathrm{~mL} / \mathrm{g}]}\end{array}$ & $\begin{array}{c}\eta_{z} \\
{[\mathrm{~mL} / \mathrm{g}]}\end{array}$ \\
\hline $\begin{array}{l}\text { PED-26 } \\
0 \mathrm{kGy}\end{array}$ & 1.920 & 0.879 & 2.04 & 4300 & 8800 & 44200 & 19.3 & 17.1 & 19.8 & 416.7 & 594.3 & 952.7 \\
\hline $\begin{array}{l}\text { PED-26 } \\
50 \text { kGy }\end{array}$ & 1.157 & 0.955 & 2.40 & 2311 & 5531 & 20650 & 25.1 & 23.0 & 25.0 & 920 & 1383 & 2581 \\
\hline $\begin{array}{l}\text { PED-26 } \\
75 \text { kGy }\end{array}$ & 0.670 & 0.792 & 2.97 & 4270 & 12690 & 83380 & 34.1 & 33.7 & 39.0 & 964 & 1409 & 2755 \\
\hline $\begin{array}{l}\text { PED-26 } \\
100 \mathrm{kGy}\end{array}$ & 0.241 & 0.259 & 4.01 & 3238 & 12990 & 71260 & 33.2 & 32.4 & 46.3 & 1220 & 1955 & 4508 \\
\hline $\begin{array}{l}\text { PED-30 } \\
0 \mathrm{kGy}\end{array}$ & 0.398 & 0.828 & 2.27 & 5600 & 12600 & 554500 & 19.6 & 19.0 & 22.8 & 498.6 & 657.2 & 963.9 \\
\hline $\begin{array}{l}\text { PED-30 } \\
50 \mathrm{kGy}\end{array}$ & 0.123 & 0.298 & 2.13 & 3670 & 7819 & 24610 & 30.7 & 30.6 & 33.2 & 1413.3 & 1836.4 & 3211.1 \\
\hline $\begin{array}{l}\text { PED-30 } \\
75 \mathrm{kGy}\end{array}$ & 0.113 & 0.331 & 2.16 & 6028 & 13000 & 49100 & 42.3 & 41.8 & 42.6 & 1312.4 & 1725.6 & 2788.9 \\
\hline $\begin{array}{l}\text { PED-30 } \\
100 \text { kGy }\end{array}$ & 0.046 & 0.149 & 1.70 & 7003 & 11920 & 26170 & 49.1 & 48.4 & 48.2 & 2162.2 & 2361.4 & 2527.4 \\
\hline
\end{tabular}

where: $M_{w} / M_{n}-$ molecular weight distribution, $M_{n}, M_{w}, M_{z}[g / m o l]$ - molecular weight, $R_{n}, R_{w}, R_{z}$-the intermediate radius of the inertia of the macromolecule $(\mathrm{nm}), \eta_{n}, \quad \eta_{w}, \quad \eta_{z}$-the intermediary radical viscosity $(\mathrm{mL} / \mathrm{g})$
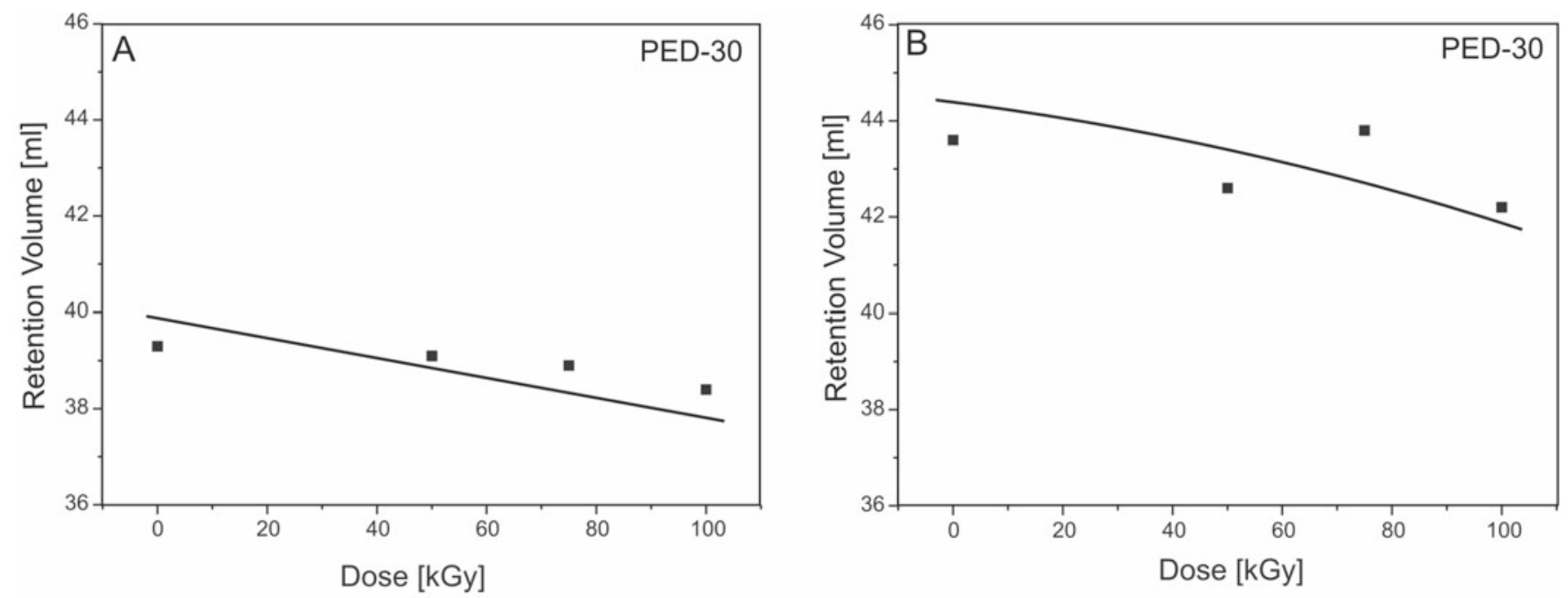

Figure 3. Changes of a retention volume of the lower MW maximum peak (a) and the higher MW maximum peak (b) for PED-30

differential scanning calorimetry (DSC). PED materials are thermoplastic elastomers showing low temperature glass transition $\left(\mathrm{T}_{\mathrm{g}}\right)$ and high temperature melting $\left(\mathrm{T}_{\mathrm{m}}\right)$ as can be seen from Table 2 .

The native „physically crosslinked” polymer structure is modified after exposure to e-beam as reflected by significant shift of $\mathrm{T}_{\mathrm{g}}$ toward lower temperatures at 100 $\mathrm{kGy}$ dose (from -51 to $-58^{\circ} \mathrm{C}$ for PED-26, and from -50 to $-56^{\circ} \mathrm{C}$ for $\mathrm{PED}-30$, respectively). Along with this change, increase of $T_{m}$ (ascribed to the hard phase) with increasing radiation dose is also observed (from 83 to $112^{\circ} \mathrm{C}$ for PED-26, and from 122 to $126^{\circ} \mathrm{C}$, respectively).
This clearly indicates that microphase separated structure is significantly changing upon e-beam irradiation, and additional chemical network within the hard segments is formed (Fig. 5).

Good illustration of the additional network formation is presented in Fig. 5. showing degree of crystallinity changes with increasing radiation dose. The content of the crystalline PBT phase in the polymer for lower hard segments content, i.e. PED-26 is gradually decreasing achieving the critical reduction in crystallinity up to $3 \%$ at $100 \mathrm{kGy}$ dose. Such value shows that there are only some crystallites capable to crystallization, and that the

Table 2. Phase transitions determined with differential scanning calorimetry for non-irradiated and electron beam-irradiated samples

\begin{tabular}{|c|c|c|c|c|c|c|c|c|}
\hline Sample & $\begin{array}{l}\text { Dose } \\
\text { [kGy] }\end{array}$ & $\begin{array}{l}\Delta \mathrm{C}_{\mathrm{p}} \\
\mathrm{J} / \mathrm{gK}\end{array}$ & $\begin{array}{l}\mathrm{T}_{\mathrm{g}} \\
{\left[{ }^{\circ} \mathrm{C}\right]}\end{array}$ & $\begin{array}{l}\mathrm{T}_{\mathrm{m}} \\
{\left[{ }^{\circ} \mathrm{C}\right]}\end{array}$ & $\begin{array}{l}\Delta \mathrm{H}_{\mathrm{m}} \\
{[\mathrm{J} / \mathrm{g}]}\end{array}$ & $\begin{array}{c}\mathrm{T}_{\mathrm{c}} \\
{\left[{ }^{\circ} \mathrm{C}\right]}\end{array}$ & $\begin{array}{c}\Delta \mathrm{H}_{\mathrm{c}} \\
{[\mathrm{J} / \mathrm{g}]}\end{array}$ & $\begin{array}{l}\mathrm{W}_{\mathrm{c}} \\
{[\%]}\end{array}$ \\
\hline \multirow{5}{*}{ PED-26 } & 0 & 0.622 & -51.5 & 83 & 8.94 & 11.2 & 8.5 & 6.2 \\
\hline & 25 & 0.762 & -51 & 94.3 & 9.7 & 13.1 & 7.9 & 6.7 \\
\hline & 50 & 0.539 & -57.4 & 98.4 & 7.2 & 10.1 & 8.4 & 5 \\
\hline & 75 & 0.520 & -56.8 & 113.6 & 7.6 & 10.5 & 7.9 & 5.3 \\
\hline & 100 & 0.555 & -58 & 112 & 5.2 & 9 & 6.2 & 3.6 \\
\hline \multirow{5}{*}{ PED-30 } & 0 & 0.570 & -50.7 & 122 & 12.5 & 33.4 & 11 & 8.7 \\
\hline & 25 & 0.400 & -51 & 122.5 & 13 & 32.3 & 12.2 & 9 \\
\hline & 50 & 0.680 & -49 & 121 & 17 & 32.3 & 12.5 & 11.8 \\
\hline & 75 & 0.580 & $\begin{array}{l}-48.3 \\
\end{array}$ & 125 & 17.3 & 32.4 & 17.6 & 12 \\
\hline & 100 & 0.444 & -56.7 & 126.5 & 12 & 32.6 & 11.6 & 8.3 \\
\hline
\end{tabular}




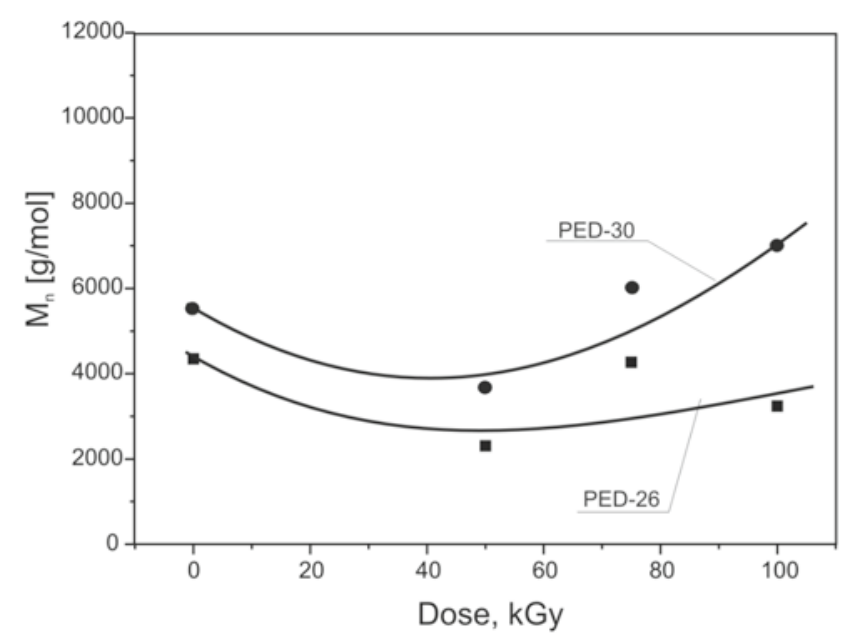

Figure 4. Changes of $M_{n}$ with increasing radiation dose for PED-26 and PED-30

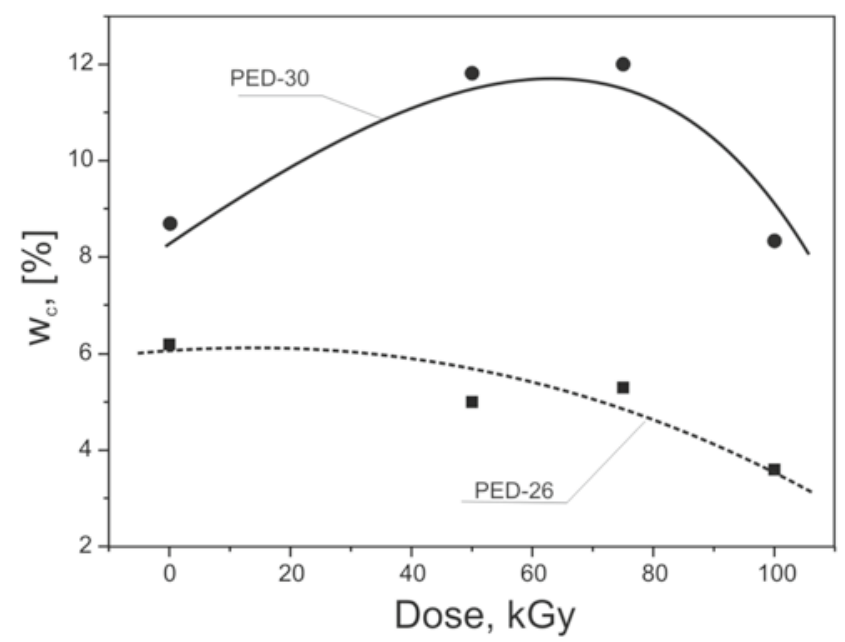

Figure 5. Degree of crystallinity of PBT in polymer (w ) versus doses of ionizing radiation: ----- PED-26, - PED-30

e-beam irradiation reconnects hard domains by chemical bonds.

In the case of PED-30 copolymer we can observe increase of the degree of crystallinity at doses of 50 and $75 \mathrm{kGy}$, while at $100 \mathrm{kGy}$, the wc dramatically decreases to the value of non modified material. The observed significant increase of the degree of crystallinity up to $75 \mathrm{kGy}$ for material containing higher hard segments content indicates significant reorganization of the hard phase domains which are randomly reconnected by newly formed chemical bonds. At high radiation dose, i.e $100 \mathrm{kGy}$ significant drop of the degree of crystallinity indicates that e-beam irradiation significantly changes microstructure due to polymer chain scission and material degradation.

\section{PED structure by wide angle $x$-ray scattering (WAXS)}

WAXS method was used to qualitatively estimate PED's physical structure and to confirm changes in polymer microstructure revealed from differential scanning calorimetry (DSC).

Fig. 6 shows diffractographs of PED 30/70 copolymer before and after modification with 50 and $100 \mathrm{kGy}$. The qualitative estimation of WAXS patterns confirms the appearance of signals ascribed to crystalline phases of PBT hard segments (see the diffractograph of the PBT homopolymer). These signals, however, are very diffused what indicates on rather low degree of crystallinity, as already found from DSC (see Table 2). Increasing dose of e-beam radiation broadens and flattens significantly these peaks what indicates on strong disturbances of the crystalline structure, and thereby on difficulties with crystallization process. This can be directly addressed to increasing role of chemical crosslinks formed upon irradiation (formation of network structure).

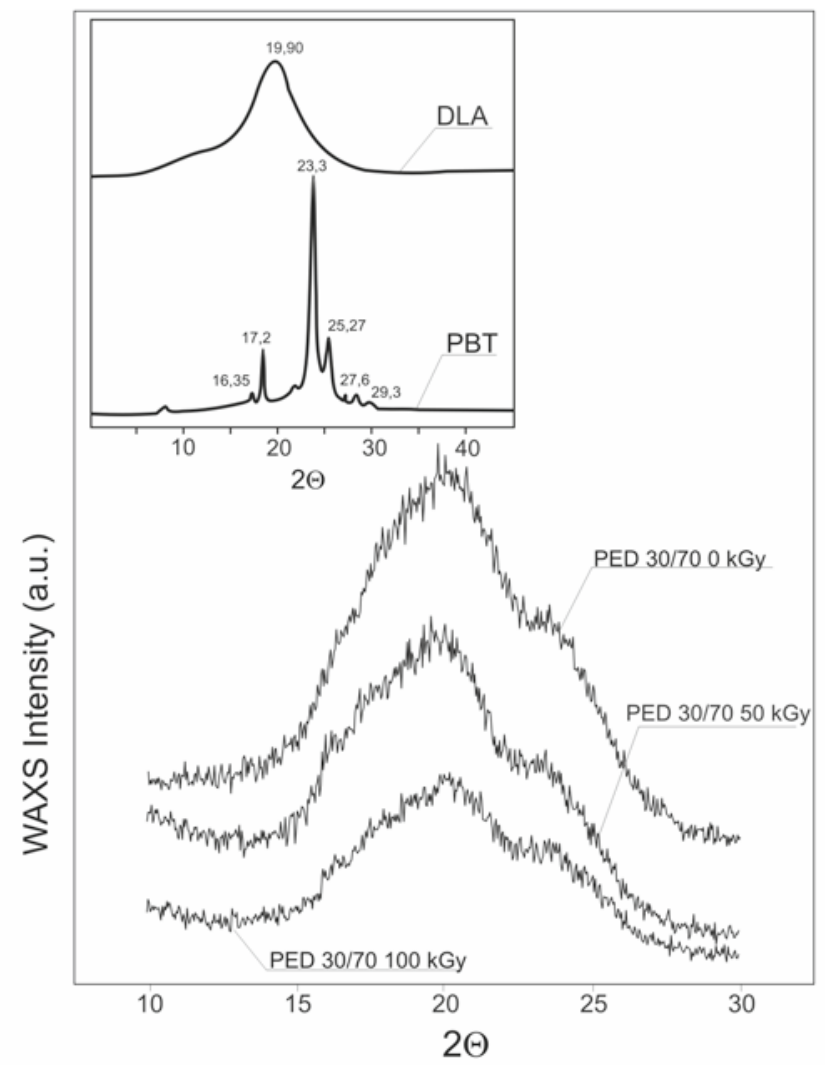

Figure 6. WAXS diffractographs for PED-30 before and after e-beam irradiation

\section{Quasi-static tensile tests}

Screening of the material mechanical behaviour was performed in order to evaluate how the e-beam irradiation and the formation of the double-network structure affects the tensile properties. Fig. 7 presents the results for $\mathrm{E}_{\bmod }, \sigma_{\max }$ and $\varepsilon_{\max }$. The comparison of the neat materials, PED-26 and PED-30, respectively, show that higher hard segments content lead to higher Young's modulus, tensile strength and elongation at break for PED-30.

The increase of mechanical properties can be related to the polymer microphase separated structure, which is better pronounced for PED-30, while at higher softphase content, i.e. PED-26, more homogeneous mixture of hard and soft segments is formed rather than the microphase separated structure. Moreover, PED-30 is stiffer than PED-26, therefore the Young's modulus increases from 7.7 MPa to 12.9 MPa. These results reveal the favourable contribution of a higher concentration of the hard phase (PBT) to enhanced mechanical properties in thermoplastic elastomers (the higher hard segments content, the higher stiffness).

Both materials, PED-26 and PED-30 have a relatively high elasticity, what can be related to the long aliphatic DLA chains in the soft phase. Fig. 7 shows that increasing e-beam irradiation dose increases $\sigma_{\max }$ and $\varepsilon_{\max }$ of the materials due to formation of the crosslinked network structure. The e-beam irradiation has no effect on Emod 

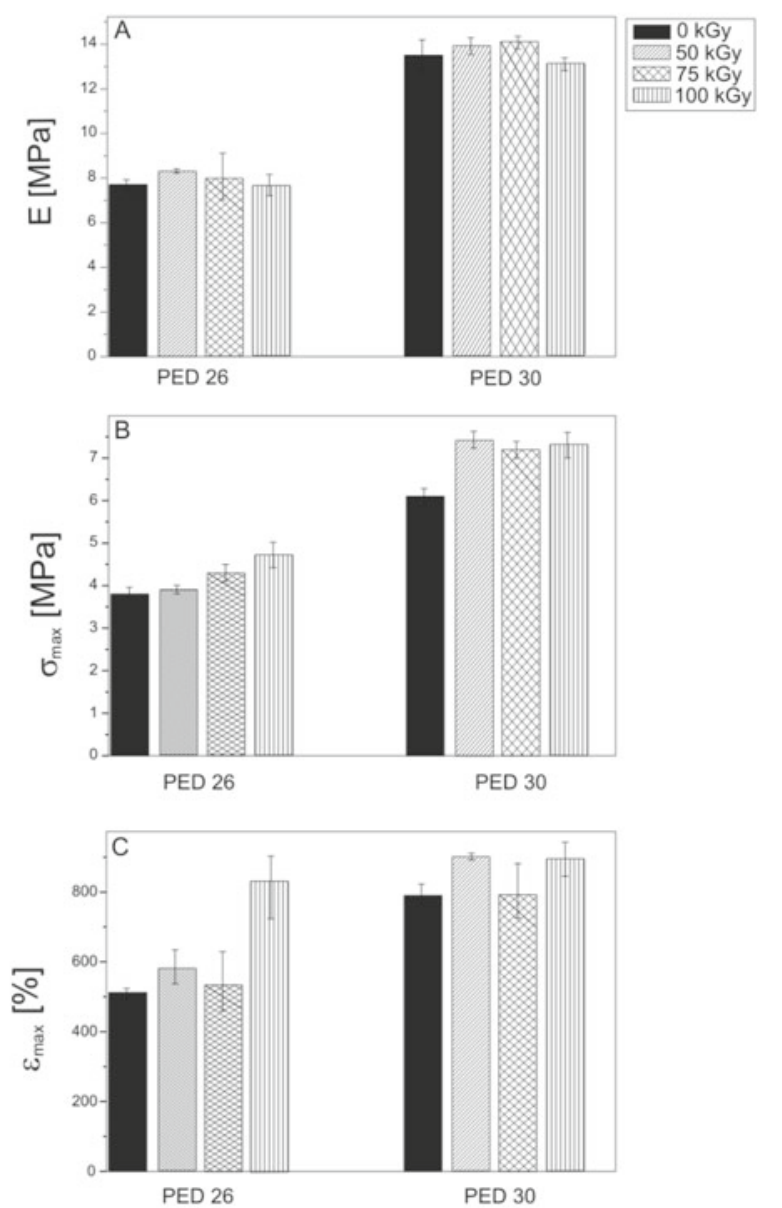

Figure 7. Static tensile properties of PED-26 and PED-30 The measurements were performed on $1 \mathrm{~mm}$ thin films with a cross-head speed of $100 \mathrm{~mm} / \mathrm{min}$

for both, PED-26 and PED-30 materials.

\section{Gel fraction}

The observed changes in mechanical properties were correlated with the gel fraction content and are showed in Fig. 8.

The Young's modulus $\left(\mathrm{E}_{\mathrm{mod}}\right)$ was higher for samples characterized by higher gel content thus indicating that mechanical properties of PED copolymers can be effectively modified with e-beam radiation which is leading to crosslinking of materials (manifested by increased gel fraction content).

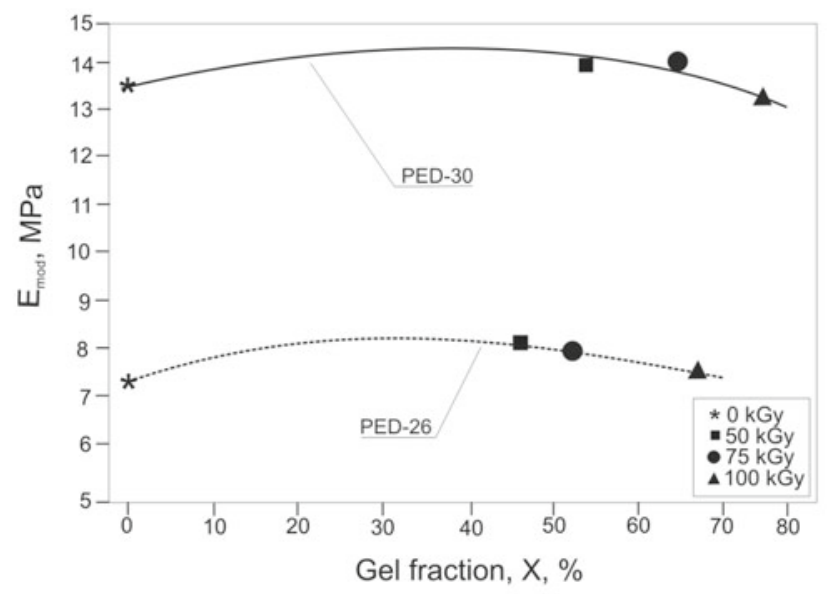

Figure 8. Young's modulus of PED-26 and PED-30 versus gel fraction content - at $0 \mathrm{kGy}$, - at $50 \mathrm{kGy}$, - at 75 $\mathrm{kGy},-$ at $100 \mathrm{kGy}$

\section{CONCLUSIONS}

Poly(aliphatic/aromatic-ester) multiblock copolymers (PEDs) modified with various dosages of e-beam irradiation were investigated to evaluate the effect of such modification on the molecular weight and structure. DSC measurements indicated that crosslinking mainly occurs within the PBT hard phase, as demonstrated by the slight increase of $\mathrm{T}_{\mathrm{m}}$ and the decrease of the crystallinity. It was found that the introduction of the additional chemical network influences the microstructure as revealed by WAXS diffractograms. The formation of an additional crosslinked network in the polymer is responsible for improving the quasi-static mechanical properties of these PED multiblock copolymers.

\section{ACKNOWLEDGEMENTS}

This work was supported by the Polish Ministry for Science and Higher Education under NN 507471838.

\section{LITERATURE CITED}

1. Wilkins, E.G., Rees, R.S., Tenenbaum, N.R., Robson, M. \& Smith, D.J. Skin and Subcutaneous Tissue Review in General Surgery. In O'Leary JP, Capote LR (eds), 2003, The Physiologic Basis of Surgery, Baltimore, MD, Williams \& Wilkins.

2. Ong, S.E., Zhang, S., Du, H., Too, H.C. \& Aung, K.N. (2007). Influence of silicon concentration on the haemocompatibility of amorphous carbon. Biomaterials, 28, pp. 4033-4038, DOI: 10.1016/j.biomaterials.2007.05.031.

3. El Fray, M., Bartkowiak, A., Prowans, P. \& Slonecki, J. (2000), Physical and mechanical behaviour of electron-beam irradiated and ethylene oxide sterilized multiblock polyester. J Mater. Sci. Mater. Med., 11, pp. 757-762, DOI: 10.1023/A:1008936114611.

4. Prowans, P., El Fray, M., Slonecki, J..(2002) Biocompatibility studies of new multiblock poly(esterester)s composed of poly(butylene terephthalate) and dimerized fatty acid. Biomaterials, 23, pp. 2973-2978, DOI: 10.1016/S0142-9612(02)00026-1.

5. Renke-Gluszko, M. \& El Fray, M.(2004), The effect of simulated body fluid on mechanical properties of multiblock poly(aliphatic/aromatic-ester) copolymers. Biomaterials, 25, pp. 5191-5198, DOI: 10.1016/j.biomaterials.2003.12.021.

6. El Fray, M. \& Slonecki, J. (1996), Multiblock copolymers consisting of polyester and polyaliphatic blocks. Angew. Mikromol. Chemie, 234, pp. 103-117.

7. El Fray, M., Przybytniak, G., Piątek-Hnat, M. \& Kornacka, E. (2010), Physical effects of radiation processes in poly(aliphatic/aromatic-ester)s modified with e-beam radiation. Polymer, 51, pp. 1133-1139, DOI: 10.1016/j.polymer.2010.01.028.

8. Mallegol, J, Carllson, DJ, Deschenes, L.(2001), Post- $\gamma$ irradiation reactions in vitamin Estabilised and unstabilised HDPE. Nucl Instr Meth Phys Res B, 185, pp. m283-293, DOI: 10.1016/S0168-583X(01)00944-2.

9. Gorna, K. \& Gogolewski, S.(2003), The effect of gamma radiation on molecular stability and mechanical properties of biodegradable polyurethanes for medical applications. Polym Degrad Stab, 79, pp. 465-474, DOI: 10.1016/S01413910(02)00362-2.

10. Gotz, C., Handge, U.A., Piatek, M., El Fray, M. \& Altstadt, V.(2009), Influence of E-Beam Irradiation on the Dynamic Creep and Fatigue Properties of Poly(aliphatic/aromatic-ester) Copolymers for Biomedical Applications. Polymer, 50, pp. 5499-5507, DOI: 10.1016/j.polymer.2009.09.051.

11. El Fray, M. \& Altstädt, V. (2003), Fatigue behaviour of multiblock thermoplastic elastomers. 2. Dynamic creep of poly(aliphatic/aromatic-ester) copolymers. Polymer, 44, pp. 4643-4650, DOI: 10.1016/S0032-3861(03)00418-X. 